\title{
Research Factors that Influence on Impulse Purchasing Behavior of Consumers in Supermarket
}

\author{
Yi Hsu \\ Associate Professor \\ Department of Business Administration \\ National Formosa University, Huwei, Yunlin, Taiwan \\ Doankimyen Mai \\ Graduate Student \\ Department of Business Administration \\ National Formosa University, Huwei, Yunlin, Taiwan
}

\begin{abstract}
Impulse purchasing behavior is a common activity with customers who buy goods without planning. This research aimed on analyzing factors that impact on the impulsive decision of buyer in supermarket. Based on an analysis of 391 samples collected from customers shopping in supermarkets and by applying the STATISTICA 10,the results showed that the three factors in the model significant positively affected on the decision of impulsive buyer, namely: Time available, Money available and shopping atmosphere. The other factors are Mood of customer, Store layout, Store staff, Store promotion and two moderate variables with insignificant in this research.
\end{abstract}

Key words: Impulse purchases, Age, Gender, Mood and feeling, Time available, Money available, Store layout, Store environment, Store staff, Salespromotion

\section{Introduction}

\subsection{ResearchBackground}

Impulse purchasing is one of the psychical issues of buyerswho are interested by researchers(Youn and Faber, 2000)and it is about $27 \%$ to $62 \%$ of purchasing behavior in whole stores (Bellenger, Robertson, and Hirschman, 1978). In addition, approximately $90 \%$ of customers occasionally engage in impulsive shopping (Welles, 1986). Impulsive shopping is an indispensable element of life and almost all of the consumers have at least once committed this behavior (Bellinger and Korganoka, 1980).

According to relevant studies, the trend of shopping behavior is related to the basic purchasing motivation of consumers. Initially, consumers' purchasing behavior with reasonable motivation, related to the utilization of purchasing experience. Moreover, there is another value that affects consumer shopping, which is the emotional value or the enjoyment value. These values can be enjoyed beyond the basic utilization of the purchasing experience. Consumers are entertained by providing relaxation atmosphere and entertainment when shopping. Going to the supermarket to stroll around and look at the items is an effective way to relieve stress, pressure and inactive moods(Saraneva and Saaksjarvi, 2008).

Consumers' satisfaction plays acrucial role in the purchasing decisionsof consumers and which is even more important when consumers shop in an excited state, when they shop without planning and spontaneously. The fact that consumers make purchasing decision at the store is a common practice in the world. According to previous studies, impromptu purchasing is accounted for 39\% at grocery stores, $62 \%$ at discount stores and 60-70\% at supermarkets (Beyza, and Leyla, 2012).

For many businesses, research on consumers' behavior is desirable to provide appropriate products and services to create a greater opportunity to attract, retain customers and increase sales. Moreover, understanding and accurately assessing the needs, attitudes, and behaviors of consumers will contribute the interaction between suppliers and consumers directly as in supermarkets, help supermarkets survive and do business successfully in this attractive but also competitive market.

\subsection{Research Purpose}

This research aims on identifying the characteristics of impulsive buyers mainly living in Vietnam and Taiwan, analyzing the factors affecting on the improvised purchase behaviour at supermarkets in these two countries. 
Base on the research results, we will make recommendations and suggestions for businesses in maximizing businessefficient, help to increase sales and profits.

\subsection{Research Question}

The research paper will attempt to collect data and answer the following questions:

- How does impulsive decision of shopper occur in supermarkets?

- What are the elements that influence onattitude of impulsive buyer when shopping at the supermarket?

- How do those factors influence on random customers' buying behavior?

\subsection{Research Process}

Chapter 1. Introduction of consumers' impulse shopping behavior, research goals, and research structure. This chapter is followed by others, namely document reviews, methods, results and discussion.

Chapter 2. Literature review gives prior studies related to the findings and definitions of all structures. This chapter shows more details about the theoretical foundations and previous studies related to the research topic that the author explored. Next is the proposal of nine hypotheses to be tested in the study.

Chapter 3. Methodology introduces conceptual model and methodology. This section represents the author's process of building the scale based on the original scales of previous studies as well as the way of surveys conducted and coded.

Chapter 4. Show the results of dissecting collected data, analyze the results in hypotheses in detail.

Chapter 5.Conclusion addresses the main findings of the study and some discussions. A number of further limitations and potential research are also addressed in this chapter.

\section{Literature review}

\subsection{Impulse purchasing behavior}

Piron (1991) has integrated the main aspects mentioned by previous researchers and proposed a comprehensive concept of improper purchase behavior that random buying is an act of buying without plan which is the result when exposed to astimulus and decision. After buying, they will experience emotional and cognitive reactions.

Impulsive purchases are still a mystery in the marketing world, accounting for a significant portion of annual sales (Weinberg and Gottwald, 1982).

\subsection{Conceptual development and hypotheses}

Age: The age is considered one of the important aspects in predicting impulse purchasing behavior. Young people face less risk when spending money (Wood, 1998). Therefore, impulse purchasing takes place at a higher level among the 18- to 39-year-old customers.

$\mathrm{H}_{1}$ : Age negatively influences on impulse buying

Gender: Gender differences will influence on the behavior of random purchase in supermarkets, Women's shopping trend is more impulsive than men(Dittmar, Beattie and Friese, 1995). They use their assets differently. Women's preference for items related to basic values for emotional purposes and relationships. Meanwhile, men prefer items related to entertainment and finance for functional purposes

$\mathrm{H}_{2}$ : Female customers shop more impulsively than male customers

Mood and feeling: Evaluated as the most crucial aspect influencing impulse purchasing behavior. Previous research (Beatty and Ferrell, 1998)shows that whether positive or negative moods also affected on this behavior. A positive mood helps stimulate improvised shopping, and conversely, impulse shopping brings sublimation, a sense of entertainment to consumers.

$\mathrm{H}_{3}$ : Mood positively impacts on the impulse buying.

Time available: The time a person spends on shopping will impact on impulsive shopping. If customers have a lot of spare time, they can spend more time on shopping (Beatty and Ferrell, 1998)

$\mathrm{H}_{4}$ : Time available positively impacts on the impulse buying

Money available: Money available is a support factor for impulse purchases (Beatty and Ferrell, 1998) because it grows an individual's ability to buy. If the individual's budget is not available, he or she will tend to avoid shopping environments

$\mathrm{H}_{5}$ : Money available positively impacts on the impulse buying 
According to previous studies of Kim (2003),external factorsinfluenceon impulsive shopping of students in supermarket, such as how to decorate inside and outside the shopping area, how to arrange the storefronts for customers and elements. In which elements of internal display and promotion have the strongest impact on consumers' purchasing intention. Especially the display of goods on the front will make a first impression to attract customers even though they have no plans to go shopping at a certain store and will attract customers to step inside (Darden,Erdem and Darden 1983). Therefore, the display of products in a store so that it is very eye-catching for shoppers is very important.

According to Cho, Ching and Luong (2014), factors affecting impulse purchase behavior of Consumer at Supermarkets are mood, scent; background music, happy atmosphere; display; employees.

$\mathrm{H}_{6}$ : Scientific store layout will increase impulse purchasing behavior

$\mathrm{H}_{7}$ : The feel of a comfortable shopping atmosphere will have a positive impact on impulsivebuyer

$\mathrm{H}_{8}$ : The enthusiasm of the staff in the supermarket will positively impact on impulse buying behavior

Zhou and $\mathrm{Gu}$ (2015) state that the price-based promotions have been increased in the last years because ofits ability to stimulate the sales and the percentage-off based on the price displayed has asignificant impact on impulsive shopping. Besides, the study of Jiyeon Kim (2003) also show that sale promotion is the strongest impact on impulse behavior.

$\mathrm{H}_{9}$ : Sales Promotion (sample, discount etc.) positively influencesonimpulsive shopping in the supermarket

From the above hypotheses, the proposed conceptual model in this study is presented as follows:

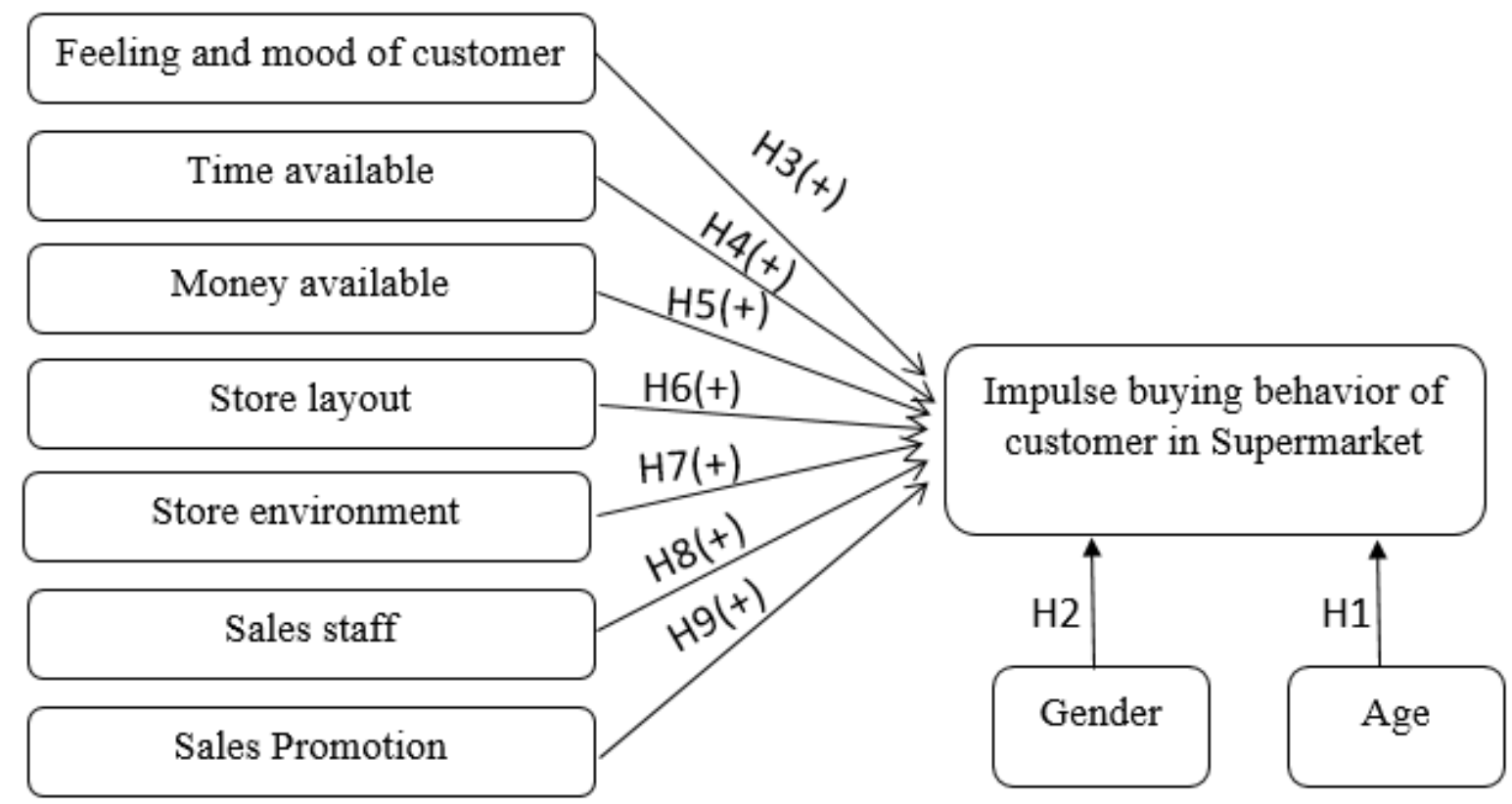

\section{Methodology}

Figure 1 The conceptual model

In this section, mainly presenting the process of conducting qualitative and quantitative research, setting up and completing questionnaires. The data was collected by questionnaires using STATISTICA 10 software to testify the relationship between factors in the proposed model and the impulse purchase of consumers. By conducting regression analysis, testing hypotheses and researching models, these parameters will help to give conclusions and recommendations.

The questionnaireswere sent to customers through Google forms and other social network platform from Jan $04^{\text {th }} 2020$ to Mar $05^{\text {th }}$ 2020. The questionnaire uses a 5-point Likert scale to evaluate, from Total Disagree $=1$ to Total Agree $=5$. The research process is carried out in 2 steps main as follows:

Qualitative research: This is a preliminary research step conducted with group discussion and trial interviews. This method is used to adjust and supplement the scale for factors affecting consumers' improper purchasing behavior.

Quantitative research: This is an official research step through questionnaire Collecting information from customers to shopping at markets and supermarkets. All data was cleaned, processed and analyzed, evaluated by STATISTICA 10. 


\section{Results}

\subsection{Demographic analysis}

Table 4.1 provides the information about the descriptive statistic demographic results of respondents. The total number for quantitative analysis consist 391 samples.

Regarding gender, males account for $48.3 \%$ of total samples with 189 samples and females accounted for $51.7 \%$ of total samples with 202 samples. Most of the candidates live in Vietnam and Taiwan, 53.7\% and 45.5\% of total samples respectively and only less than $1 \%$ of the candidates live in another country. In terms of age, the age group accounts for the highest proportion is from 18 to 25 years, with $49.4 \%$ of total samples, followed by age group 26-35 with $31.5 \%$ of total samples. The next three age groups are 36-45, under 18 and 46-55, account for $8.9 \%, 5.1 \%$, and $4.9 \%$ of total samples, respectively. The age group is over 55 with only a sample accounting for $0.2 \%$. The income distribution is mainly moderate; a majority of samples (53.5\% of total samples) have an average monthly income between USD 250500. This shows that the survey samples are sufficiently diverse for statistical analysis.

Table 4.1. Demographic Statistics

\begin{tabular}{llllll}
\hline Items & Frequency & Percentage (\%) & Items & Frequency & Percentage (\%) \\
& & & & \\
\hline Gender & & & Living & \\
Male & 189 & 48.3 & Vietnam & 210 & 53.7 \\
Female & 202 & 51.7 & Taiwan & 178 & 45.5 \\
& & & Other & 3 & 0.8 \\
Age & & & Monthly Income & \\
$<18$ & 20 & & $<\$ 250$ & 33 & 8.4 \\
$18-25$ & 193 & 5.1 & $\$ 250-\$ 500$ & 209 & 53.5 \\
$26-35$ & 123 & 49.4 & $\$ 501-\$ 1000$ & 106 & 27.1 \\
$36-45$ & 35 & 8.9 & $>\$ 1000$ & 43 & 11 \\
$46-55$ & 19 & 4.9 & & & \\
$>55$ & 1 & 0.2 & & & \\
Status & & & & \\
Single & 277 & 70.8 & & & \\
Married & 114 & 29.2 & & & \\
\hline
\end{tabular}

\subsection{Regression analysis}

Table 4.2 Regression Model

\begin{tabular}{|c|c|c|c|c|}
\hline \multicolumn{5}{|c|}{ Model Summary } \\
\hline Model & $\mathrm{R}$ & $\mathrm{R}^{2}$ & Adjusted $\mathrm{R}^{2}$ & $\mathrm{P}$ value \\
\hline 1 & 0.869 & 0.756 & 0.749 & 0.000 \\
\hline \multicolumn{5}{|c|}{ Coefficients } \\
\hline 1 & & Coefficient & $\mathrm{T}$ value & $\mathrm{P}$ value \\
\hline & (Constant) & 0.158 & 0.993 & 0.322 \\
\hline & Mood of customer & 0.048 & 1.036 & 0.301 \\
\hline & Time available & 0.338 & 7.229 & 0.000 \\
\hline & Money available & 0.379 & 8.163 & 0.000 \\
\hline & Store layout & 0.034 & 0.788 & 0.431 \\
\hline & Shopping atmosphere & 0.169 & 3.233 & 0.001 \\
\hline & Sales staff & -0.072 & -1.317 & 0.189 \\
\hline & Sales Promotion & 0.051 & 0.904 & 0.367 \\
\hline & Male & -0.036 & -0.415 & 0.678 \\
\hline & Female & 0.036 & 0.415 & 0.678 \\
\hline & Age & 0.001 & 0.368 & 0.713 \\
\hline
\end{tabular}

From table 4.2 we can see, the model has $\mathrm{R}^{2}$ is 0.756 and Adjusted $\mathrm{R}^{2}$ is 0.749 , $\mathrm{P}$ value results in 0.000 , lower than the significance level of 0.05 , hence, the built regression model is suitable. The regression equation based on $\mathrm{B}$ is: 


\begin{tabular}{ccccc} 
Impulse Purchasing $=$ & 0.158 & +0.048 Mood of customer & +0.338 Time available \\
& $(0.993)$ & $(1.036)$ & $(7.229)$ \\
$(0.322)$ & $(0.301)$ & $(0.000)$ \\
+0.379 Money available & +0.034 Store layout & +0.169 Shopping atmosphere \\
$(8.163)$ & $(0.788)$ & \multicolumn{2}{c}{$(3.233)$} \\
$(0.000)$ & & $(0.431)$ & $(0.001)$ \\
-0.072 Sales staff & +0.051 Sales Promotion & -0.036 Male & +0.036 Female & +0.001 Age \\
$(-1.317)$ & $(0.904)$ & $(-0.415)$ & $(0.415)$ & $(0.368)$ \\
$(0.189)$ & $(0.367)$ & $(0.678)$ & $(0.678)$ & $(0.713)$
\end{tabular}

Based on the outcomes in Table 4.3 shows that only three factors Time available $(B=0.338, P=0.000)$, Money available $(B=0.379, P=0.000)$ and Store environment $(B=0.169, P=0.001)$ have significantly positive influences on impulse purchasing of customers in supermarkets. The higher the coefficient means the greater the influence of that factor on the impulsive buyers, and the lower the coefficient means the lower the effect of that element on the impulsive buyers. Consumer inspiration is declining. Therefore, $\mathrm{B}=0.379$ is the largest of the analyzed factors, so Money availableis the most important factor that positively influences on impulsive shopping. The Time available and Shopping atmosphereare also two factors that have significantly positive impact on the $\mathrm{B}=0.383$ and 0.169 respectively. The remaining variables such as Mood of customer $(B=0.408 \mathrm{P}=0.301)$, Store layout $(\mathrm{B}=0.034, \mathrm{P}=0.431)$, Sales staff $(\mathrm{B}=-0.072, \mathrm{P}=0.189)$, Sales Promotion $(\mathrm{B}=0.051, \mathrm{P}=0.367)$, so we can conclude that the above variables do not influence on decision of impulsive buyers

Table 4.3Results of Regression

\begin{tabular}{llccc}
\hline & \multicolumn{1}{c}{ Hypothesis } & Coefficient & P-value & Results \\
\hline H1 & Age $\rightarrow$ Impulse purchasing & 0.001 & 0.713 & Rejected \\
H2 & Male $\rightarrow$ Impulse purchasing & -0.036 & 0.678 & Rejected \\
& Female $\rightarrow$ Impulse purchasing & 0.036 & 0.678 & Rejected \\
H3 & Mood $\rightarrow$ Impulse purchasing & 0.048 & 0.301 & Rejected \\
H4 & Time available $\rightarrow$ Impulse purchasing & 0.338 & $0.000^{*}$ & Supported \\
H5 & Money available $\rightarrow$ Impulse purchasing & 0.379 & $0.000^{*}$ & Supported \\
H6 & Store layout $\rightarrow$ Impulse purchasing & 0.034 & 0.431 & Rejected \\
H7 & Shopping atmosphere $\rightarrow$ Impulse purchasing & 0.169 & $0.001^{*}$ & Supported \\
H8 & Sale staff $\rightarrow$ Impulse purchasing & -0.072 & 0.189 & Rejected \\
H9 & Sale promotion $\rightarrow$ Impulse purchasing & 0.051 & 0.367 & Rejected \\
\hline \multicolumn{2}{r}{$*$ P $<0.05$} & & &
\end{tabular}

4.3T-test analysis for Genders concerning customer's impulse purchasing behavior

Table 4.4 T-Test Results

\begin{tabular}{ccccc}
\hline \multicolumn{5}{c}{ T-test analysis } \\
\hline Impulse & Mean of Female & Mean of Male & T-value & P value \\
\hline Purchasing & 3.553 & 3.909 & -4.904 & 0.000001 \\
\hline
\end{tabular}

The above result shows that the differences are significantin the impulsive shopping behavior among different gender groups of customers" with T-value is -4.904 and P-value is $0.000001(<0.05)$. However, the mean value of the male is higher than female with the mean value representing females is 3.553 and the Mean value of the male is 3.909.

\subsection{ANOVA analysis for Age about customer's impulse purchasing behavior}

Table 4.5 ANOVA analysis

\begin{tabular}{cccc}
\hline Age & Mean & F value & P value \\
\hline$<18$ & 3.150 & 5.791 & 0.000036 \\
$18-25$ & 3.728 & & \\
$26-35$ & 3.941 & & \\
$36-45$ & 3.593 & & \\
$46-55$ & 3.421 & & \\
$>55$ & 3.250 & & \\
\hline
\end{tabular}


Table 4.6 Post Hoc test Results - Bonferroni test

\begin{tabular}{ccccccc}
\hline The age & $<18$ & $18-25$ & $26-35$ & $36-45$ & $46-55$ & $>55$ \\
& $(3.150)$ & $(3.728)$ & $(3.941)$ & $(3.593)$ & $(3.421)$ & $(3.250)$ \\
\hline$<18$ & & 0.010 & 0.000 & 0.423 & 1.000 & 1.000 \\
$18-25$ & 0.010 & & 0.154 & 1.000 & 1.000 & 1.000 \\
$26-35$ & 0.000 & 0.154 & & 0.175 & 0.052 & 1.000 \\
$36-45$ & 0.423 & 1.000 & 0.175 & & 1.000 & 1.000 \\
$46-55$ & 1.000 & 1.000 & 0.052 & 1.000 & & 1.000 \\
$>55$ & 1.000 & 1.000 & 1.000 & 1.000 & 1.000 & \\
\hline
\end{tabular}

According to the ANOVA results as table 4.6, demonstrate that Age has an effect on impulse purchasing (F-value $=$ 5.791, p-value $=0.000036$ ). In particular, the Mean of the age group 26-35 is the highest (3.941) so this age group purchases more randomly than the remaining groups.

From the post hoc test, Bonferroni test, 3 groups with a difference in random shopping. Specifically, the age group under 18 and the group 18-25 have the difference in impulse shopping with $\mathrm{P}=0.010$ and the age group under 18 with the age group 26-35 has the difference in improvising shopping with $\mathrm{P}=0.000$.

\section{Discussion and Conclusion}

The target of this study is to identify and exploit the elements that affect impulsive decision of buyer in supermarkets. In addition, we also analyze the relationship between the factors affecting decision of impulsive buyerwho live mainly Asian countries - Taiwan and Vietnam.

According to previous relevant studies, the topic has proposed a research model consisting of 9 variables, of which 7 independent variables and 2 demographic variables are age and gender. The only dependent variable in this study is the customer's impulse shopping behavior.

Based on the result of regression analysis between the dependent and independent variables, only three factors have statistical significance, namely money available, time available and store atmosphere. The four factors that hadinsignificantinfluences on impulse purchasing behavior in supermarketsare mood, layout, staff, and promotion. According to ANOVA analysis results, the Independent ofSample T - Test and the evaluation of demographic factors, there are significant differences in impulse purchasing behavior among different gender groups, age groups.

\subsection{Discussion of results}

$\mathrm{H}_{1}$ : Age negatively influences on impulse buying. The result rejected $\mathrm{H}_{1}$ which has been supported by Wood (1998).The result is age insignificantly positive influences on impulse buying.

This research rejectedH $\mathrm{H}_{1}$ due to following reasons.All ages have the need and desire to go to the supermarket to shop. Making an impulsive decision is gradually becoming a dailyactivity, especially in developed countries like Taiwan and young dynamic countries like Vietnam. In addition, research of Wood took places in 20 years ago and was conducted in Europe where are differences in shopping habits compared to Asian countries.In Asian, not only youngpeople tend to shop but also the middle-aged and the old like to shop because they went through hard times in the 1990s where goods were scarce so now they are eager to shop (Cho, Ching and Luong, 2014). Moreover, they also have money availability and time availability.

$\mathrm{H}_{2}$ : Female customers shop more impulsively than male customers. The differences are significant but the mean value of the male is higher than female.The results rejected $\mathrm{H}_{2}$ and do not support previous research(Dittmar, Beattie and Friese, 1995). Although women are almost responsible for their daily shopping tasks and prefer to shop during free time than men, they are often considered family-oriented and manage family expenses.Therefore, the shopping behavior of woman in Asian countries such as Vietnam and Taiwan at supermarkets gradually formed the habit of buying goods more carefully to serve the family's needs.In contrast, when it comes to buying tasks, men are less experienced in bargaining and making less judgmental efforts than women, so tend to buy things without much consideration.

The result of $\mathrm{H}_{3}$ : Mood positively impacts on the impulse buying is rejected. And the result can be explained by the below reason. Most respondents are from 18-35 years old, are adults and tend to spend reasonably and less impulsively. Especially, according to the survey, most of the respondents live in Vietnam and Taiwan, are Asian countries and their income is not too high, so the emotional shopping will be limited. 
$\mathrm{H}_{4}$ : Time availablepositively impacts on the impulse buyingand and $\mathrm{H}_{5}$ : Money available positively impacts on the impulse buyingare supported. Both of them positively impact on impulse purchasing. If customers have a lot of spare time and their budget is available, their tend ismore shopping (Beatty and Ferrell, 1998)

The result of $\mathrm{H}_{6}$ : Scientific store layout will increase impulse purchasing behavior is rejected. The reason is if they do shop spontaneously, they would not spend much time researching the store. Shoppers are likely to suddenly arise shopping needs without careful consideration. When demand is satisfied, they will not buy back at the store.

$\mathrm{H}_{7}$ : The feel of a comfortable shopping atmosphere will have a positive impact on impulsive shoppers is supported. The result is supported by the research of Cho, Ching, and Luong (2014). The study shows the elements affecting on behavior of impulsive buyer at supermarkets, including the shopping atmosphere.

$\mathrm{H}_{8}$ : The enthusiasm of the staff in the supermarket will positively impact on impulse buying and $\mathrm{H}_{9}$ : Sales Promotion (sample, discount etc.) positively influenceson impulsive shopping are rejected. The shopping that is impulsive may take place in just a few minutes while they are walking around in the supermarket. Therefore, regardless of whether the salesperson's appearance or the price promotiondoes not have much influence on their impulse purchasing decisions.

\subsection{Limitations and Further research}

Besides these achievements, the research also has several limitations. This study only considers several factors that directly affect the impulse purchases, which can have many other factors that influence on impulse purchasing

- The number of study samples is small, so it has not shown the representation.

- Online sample collection method partly affects the distribution of research samples, which is not reasonable, mainly falls in the age of 18 to 35 years old, so the data collected may not be highly reliable

Some further research directions for the topic are proposed as follows:

- Expanding the scope of research to various types of retail stores such as grocery stores, mini supermarkets, traditional stores, online shopping ... instead of limiting the scope of shopping behavior at supermarkets

- Compare the customers' impulse purchasing habits with different types of stores, for example between traditional markets and supermarkets, between traditional purchases and online purchases

- Research the impulse purchasing behavior of the customers on different types of products and compare them. For example, the act of improper purchasing for essential products and the act of improper purchasing for luxury products

\section{References}

[1] Bellenger, D.N, Robertson, \& Hirschman (1978). Impulse buying varies by product. Journal of Advertising Research, 18 (6), 15-18

[2] Beatty, S. E., \& Ferrell, M. E. (1998). Impulse Buying: Modeling its Precursors. Journal of Retailing, 74(2), 169-191

[3] Beyza, G., \& Leyla, Ö. (2012). The Influence of Hedonic Motives and Browsing On Impulse Buying. Journal of Economics and Behavioral Studies, 4(3), 180-189

[4] Cho, J., Ching, G. S., \& Luong, T.H. (2014). Impulse buying behavior ofVietnamese consumers in supermarket setting. International Journal ofResearch Studies in Management, Vol. 3(2)

[5] Darden, W.R., Erdem, O., \& Darden, D.K., (1983). A comparison and test of three casual models of patronage intentions,patronge behavior and retail management. New York: North Holland. 29-43

[6] Dittmar, H., Beattie, J., \&Friese, S. (1995). Gender Identity and Material Symbols: Objectsand Decision Considerations in Impulse Purchases. Journal of Economic Psychology, 16(3),491-511

[7] Kim, J. (2003). College student's apparel impulse behaviors in relation to visual merchandising.Master of Science thesis in department of Textiles, Merchandising, and Interiors atUniversity of Georgia Theses and Dissertations

[8] Piron, F. (1991). Defining Impulse Purchasing. Advances in Consumer Research, 18(1), 509-514.

[9] Saraneva, A., Saaksjarvi, M. (2008). Young compulsive buyers and the emotional roller- coaster in shopping. Young customers: insight and ideas for responsible marketers, 9(2), 75-89.

[10] Welles, G. (1986). We're in the habit of impulsive buying. USA Today, 1

[11] Weinberg, P., \&Gottwald, W. (1982). Impulsive Consumer Buying As A Result OfEmotions," Journal of Business Research, 10(1), 43-57

[12] Wood, M. (1998). Socio-economic status, delay of gratification, and impulse buying. Journal of EconomicPsychology, 19(3), 295-320

[13] Youn, S., \&Faber, J.R. (2000). Impulse Buying: Its Relation to Personality Traits and Cues. Association for Consumer Research, 27(1), 179-185.

[14] Zhou, H. Gu, Z. (2015). The effect of different price presentations on consumer impulse buying behavior. The role of anticipated regret. American Journal of Industrial and Business Management, 5, 27-36. 